\title{
CORRECTION
}

\section{Correction to: Corrosion Level of Rock Bolts Exposed to Aggressive Environments in Nordic Road Tunnels}

\author{
Cristobal Javier Manquehual ${ }^{1}$ (1) $\cdot$ Pål Drevland Jakobsen $^{1} \cdot$ Amund Bruland $^{1}$
}

Published online: 24 July 2021

(c) Springer-Verlag GmbH Austria, part of Springer Nature 2021

\section{Correction to: Rock Mechanics and Rock Engineering https://doi.org/10.1007/s00603-021-02547-3}

In the original publication, Fig. 1 and Fig. 3 were published incorrectly (without arrows), the correct figures are provided in this correction.

Fig. 1 Probabilistic limit-state approach for predicting the useful life applied to rock bolt corrosion. Modified from standard ISO 13823 (2008)

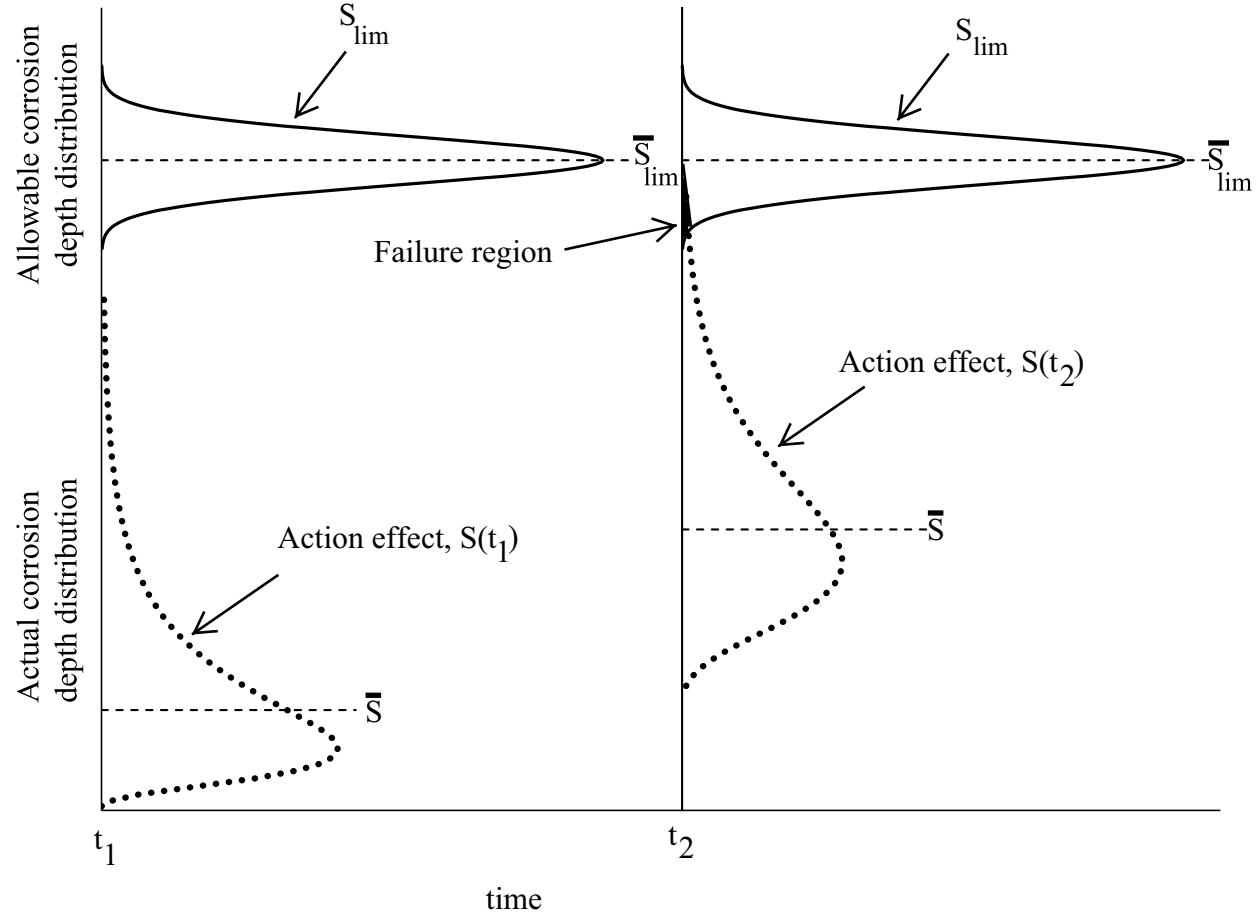

The original article can be found online at https://doi.org/10.1007/ s00603-021-02547-3.

Cristobal Javier Manquehual

cristobal.j.manquehual@ntnu.no

Department of Civil and Environmental Engineering,

Norwegian University of Science and Technology,

Høgskoleringen 7A, 7034 Trondheim, Norway 
(a)
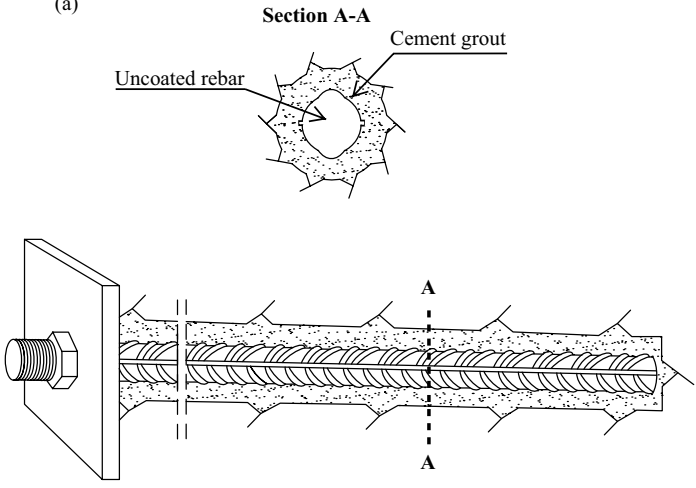

(b)

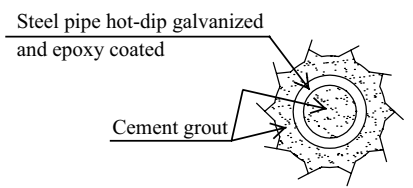

(c)

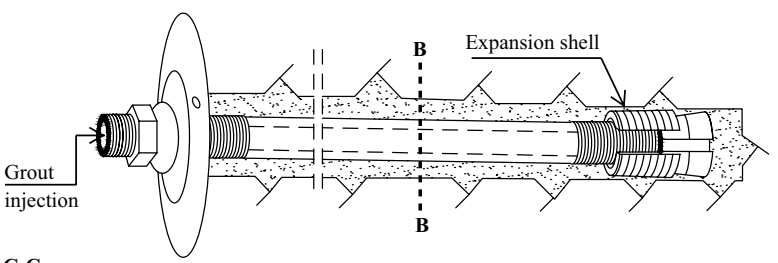

Section C-C
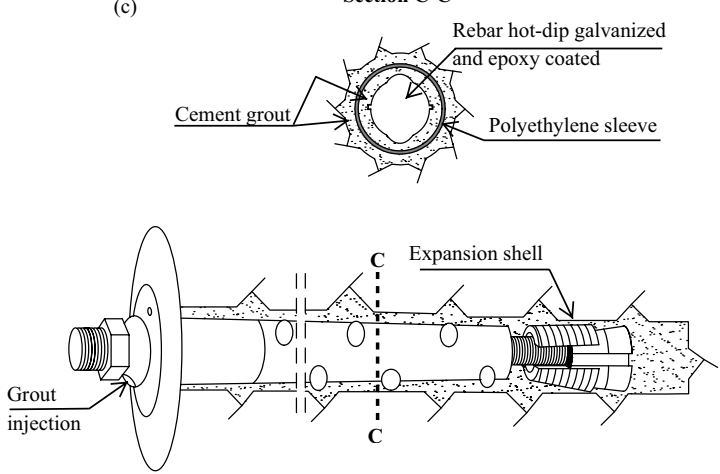

Fig. 3 Some rock bolts used as permanent rock supports in Norwegian road tunnels. a Uncoated rebar cement grouted in the Haukeli road tunnel constructed between 1968 and 1969. The rebar is 20 $\mathrm{mm}$ in diameter and $2.4 \mathrm{~m}$ long (Pedersen and Hafsaas 1991). b Pipe bolt used in Byfjord and Mastrafjord subsea road tunnels constructed between 1989 and 1992. The 3-m-long rock bolt, steel pipe and accessories are hot-dip galvanized and epoxy coated (Espedal and Nærum 1992). c CT-Bolt used in the Frøya subsea road tunnel constructed between 1998 and 2000. The 3-m-long rock bolt, rebar and accessories are hot-dip galvanized and epoxy coated (Holmøy et al. 2009)

Publisher's Note Springer Nature remains neutral with regard to jurisdictional claims in published maps and institutional affiliations. 